Conference Proceedings Paper

\title{
Moisture Sources Identification of Tropical Cyclones in the North Atlantic
}

\author{
Marni Pazos 1,* and Luis Gimeno ${ }^{2}$ \\ Published: 15 July 2016 \\ 1 EPhysLab, Facultade de Ciencias, Universidade de Vigo, Ourense 32004, Spain \\ 2 Universidad Nacional Autónoma de México; l.gimeno@uvigo.es \\ * Correspondence: marnipazos@gmail.com or marni@unam.mx; Tel.: +52-554-187-1165
}

\begin{abstract}
In this study, we identified the moisture sources of 110 tropical cyclones with cyclogenesis within the area comprised between $15-45^{\circ} \mathrm{W}$ and $8-20^{\circ} \mathrm{N}$. We used the Lagrangian FLEXPART model to perform the analysis that computes the changes in the specific humidity of ten days before the day of cyclogenesis of each tropical cyclone and its contribution to the moisture budget of the region of interest. Then we calculated the anomaly values of the results to identify the main regions of moisture sources: The African coasts in the North Atlantic, the continental region over western Africa and the area along the South Atlantic from the Equator to the Southern Africa coast.
\end{abstract}

Keywords: tropical cyclones; moisture sources; lagrangian analysis

\section{Introduction}

The aim of this work is to acquire a better understanding of the role of tropical cyclones (TCs) in global moisture distribution and the social and economic effects that produce at landfall. Through the study of moisture transport from ocean sources which contributes to the cyclogenesis and development of TCs, we will approach to characterize the climatology especially for those reaching extra-tropical latitudes, from both the zones where the cyclogenesis is carried out and zones of their main path.

The identification of moisture sources can be performed through lagrangian analysis, where changes in the amount of moisture of an air parcel, due to evaporation or precipitation, are assessed along an air parcel trajectory from one point of interest to another, identifying those places where moisture is gained or lost [1]. The main tool that we used to analyze moisture sources is the method developed by Stohl and James [2], the Flexible Particle dispersion model (FLEXPART) is a Lagrangian transport and dispersion model suitable for the simulation of a large range of atmospheric transport processes, and has been a highly efficient to diagnose changes in specific humidity along several trajectories related to sink regions [3-6].

There are previous studies about moisture sources and TCs [7,8], however, scarce studies on lagrangian analysis have been applied [9].

In this paper, we describe first the TCs data base used and its characteristics, as well as the areas of interest of moisture sources, and we further the obtained results from the lagrangian model. 
The 1st International Electronic Conference on Atmospheric Sciences (ECAS 2016), 16-31 July 2016;

Sciforum Electronic Conference Series, Vol. 1, 2016

\section{Data and Method}

TCs data was obtained from the Nation Hurricane center, HURDAT 2nd generation, available from http://www.aoml.noaa.gov/hrd/hurdat/hurdat2-2051-2014-022315.html.

From HURDAT data set, we selected the records from 1979 to 2012, corresponding to the time span used by FLEXPART and ERA-Interim Reanalysis Data used in order to calculate the moisture sources. We selected only the storms identified as tropical storm or hurricane in the first line of the record or cyclogenesis and it should be located inside the region comprised between $15-45^{\circ} \mathrm{W}$ and $8-20^{\circ} \mathrm{N}$, obtaining 110 events (Figure 1).

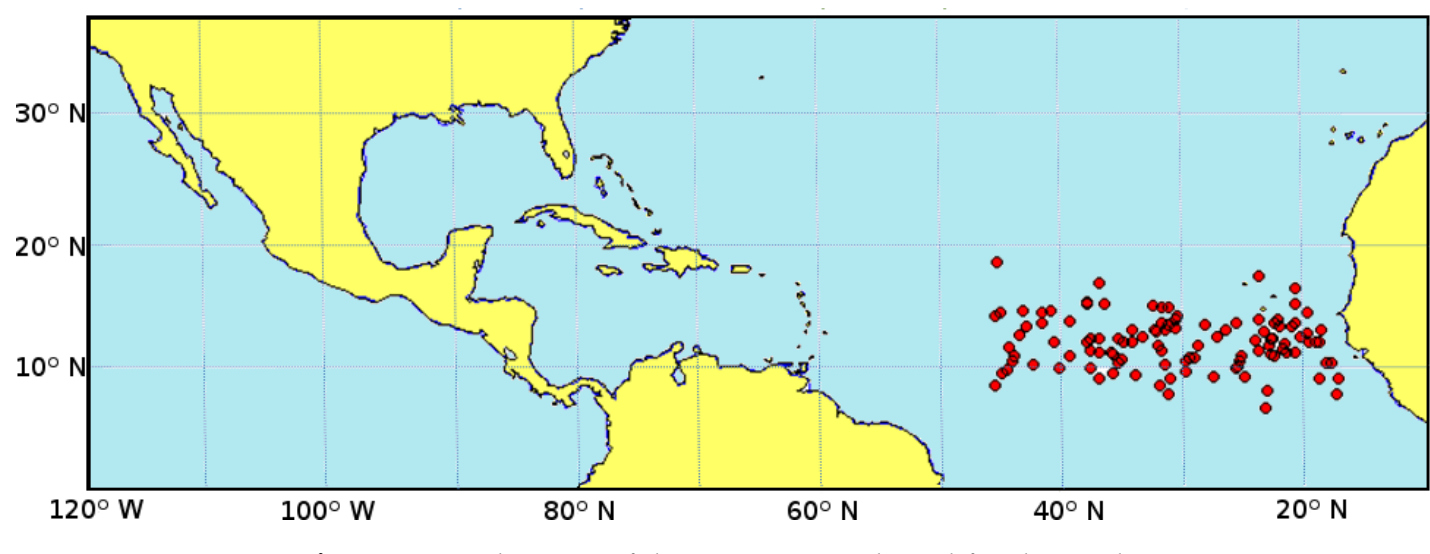

Figure 1. Localization of the 110 events selected for the study.

We calculated boxes of six by six degrees with the center in the position of the cyclogenesis given by the records. Given the corners of the boxes to the FLEXPART model, as well as the corresponding day and month of each event, we obtained the sum of all values of specific humidity from the moisture sources related to the particles inside the box, 10 days before to the day of the event in each year from 1979 to 2012, in order to calculate the anomalies of moisture sources related to date of the event, the same procedure was performed for the 110 events.

\section{Results and Discussion}

Figure 2, shows a map with the results of the sum of anomalies calculated for the 110 events, where the moisture sources for the TCs originated in the region of interest can be identified by the areas colored in yellow, orange and red, indicating the values of the anomalies.

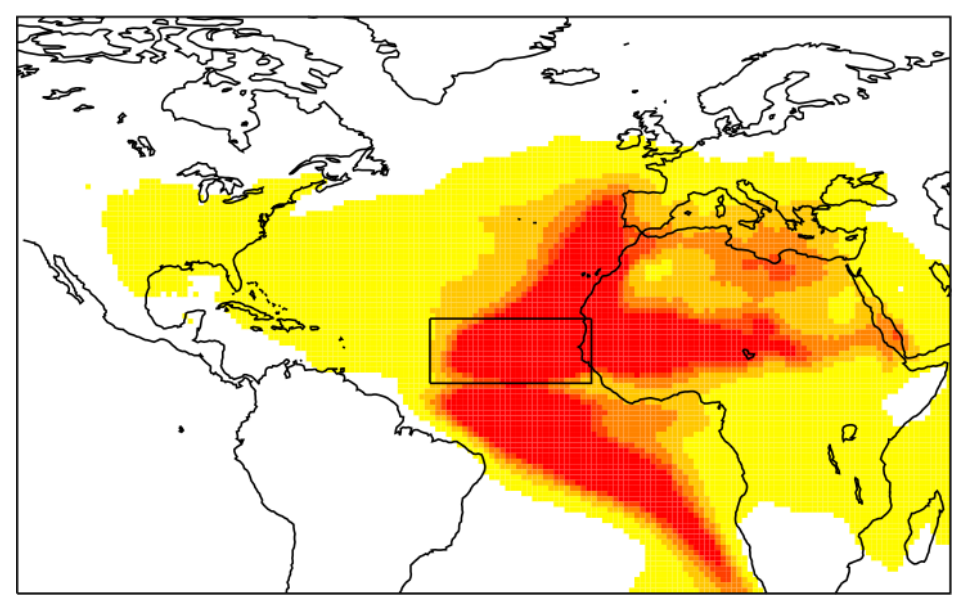

Figure 2. Accumulated of the anomalies of moisture sources from the $110 \mathrm{TCs}$ originated in the area defined by the box. 
The 1st International Electronic Conference on Atmospheric Sciences (ECAS 2016), 16-31 July 2016; Sciforum Electronic Conference Series, Vol. 1, 2016

The higher values are found in two main areas: in the north Atlantic front to the African coast, over west Africa, possibly due to the easterly African jet [10], and the area extended along the south Atlantic from the equator through the southern African coast.

The gap between regions of moisture sources seems to be divided by the intertropical convergence zone.

\section{Conclusions}

Modeling the patterns of the anomalies of moisture sources related to specific tropical cyclones, we were able to establish several areas of the possible provenance of these sources.

The South Atlantic area has a complex dynamic that seems to play an important role in the North Atlantic tropical cyclogenesis. The use of FLEXPART on the identification process shows to be a novel tool. Few studies have been conducted on the moisture sources of tropical cyclones. According to Wang et al. [8], the large Atlantic warm pool, associated with a decrease in sea level pressure and an increase in atmospheric convection and cloudiness, corresponds to a weak tropospheric vertical wind shear and a deep warm upper ocean, making a favorable environment for hurricane development, although it is not suggested the origin of the moisture sources of the convection and cloudiness, which as we can see from the results they are not local.

Acknowledgments: CONACyT grant 264009.

Author Contributions: L. Gimeno conceived and designed the experiments; M. Pazos performed the experiments; M. Pazos and L. Gimeno analyzed the data; M. Pazos and L. Gimeno wrote the paper.

Conflicts of Interest: The authors declare no conflict of interest.

\section{Abbreviations}

The following abbreviations are used in this manuscript:

TCs tropical cyclones

\section{References}

1. Sodeman, H.; Schwierz, C.; Wernli, H. Interannual variability of Greenland winter precipitation sources: Lagrangian moisture diagnostic and North Atlantic Oscillation influence. J. Geophys. Res. 2008, 113, D031107, doi: 10.1029/2007JD008503.

2. Stohl, A.; James, P. A Lagrangian analysis of the atmospheric branch of the global water cycle. Part II: Moisture transports between the Earth's ocean basins and river catchments. J. Hydrometeorol. 2005, 6, 961-984.

3. Gimeno, L.; Nieto, R.; Trigo, R.M.; Vicente-Serrano, S.; Moreno, J.I.L. Where does the Iberian Peninsula moisture come from? An answer based on Lagrangian approach. J. Hydrometeorol. 2010, 11, 421-436.

4. Gimeno, L.; Nieto, R.; Drumond, A.; Durán-Quesada, A.M.; Stohl, A.; Sodemann, H.; Trigo, R.M. A close look at oceanic sources of continental precipitation. EOS Trans. AGU 2011, 92, doi:10.1029/2011EO230001.

5. Gimeno, L.; Nieto, R.; Drumond, A.; Castillo, R.; Trigo, R.M. Influence of the intensification of the major oceanic moisture sources on continental precipitation. Geophys. Res. Lett. 2013, doi: 10.1002/grl.50338.

6. Nieto, R.; Castillo, R.; Drumond, A.; Gimeno, L. A catalog of moisture sources for continental climatic regions. Water Resour. Res. 2014, doi:10.1002/2013WR013901.

7. Wang, C.; Lee, S.K.; Enfield, D.B. Impact of the Atlantic Warm Pool on the Summer Climate of the Western Hemisphere. J. Clim. 2007, 21, 5021-5040, doi:10.1175/JCLI4304.1.

8. Wang, C.; Lee, S.K.; Enfield, D.B. Climate response to anomalously large and small Atlantic warm pools during the summer. J. Clim. 2008, 21, 2437-2450, doi:10.1175/2007JCLI2029.1.

9. Drumond, A.; Nieto, R.; Gimeno, L. On the contribution of the Tropical Western Hemisphere Warm Pool source of moisture to the Northern Hemisphere precipitation through a Lagrangian approach. J. Geophys. Res. 2011, 116, D00Q04, doi:10.1029/2010JD015397. 
The 1st International Electronic Conference on Atmospheric Sciences (ECAS 2016), 16-31 July 2016;

Sciforum Electronic Conference Series, Vol. 1, 2016

10. Hopsch, S.B.; Thorncroft, C.D.; Tyle, K.R. Analysis of African Easterly Wave Structures and Their Role in Influencing Tropical Cyclogenesis. Mon. Weather Rev. 2010, 138, 1399-1419.

11. HURDAT Re-Analysis. Available online: http://www.aoml.noaa.gov/hrd/hurdat/hurdat2-1851-2015-021716.txt (accessed on 30 June 2016).

(C) 2016 by the authors; licensee MDPI, Basel, Switzerland. This article is an open access article distributed under the terms and conditions of the Creative Commons by Attribution (CC-BY) license (http://creativecommons.org/licenses/by/4.0/). 